\title{
Transcribed, Translated, Transplanted: With Professor Keiko Beppu on James Studies in Japan
}

DOI: http://dx.doi.org/10.12775/LC.2017.019

\section{Dorota Guttfeld: Professor Beppu, what do you recall as the greatest challenge in your translation of A Henry James Encyclopedia? ${ }^{1}$}

Prof. Keiko Beppu: A major challenge is the transcription of proper nouns-names of people, and of places, and names of fictional characters, all of which have a few acceptable readings in Japanese. Since I worked with another person on the translation of Encyclopedia, Japanese readings of proper nouns should be uniform and consistent throughout the whole volume. Fortunately, A Guide to Japanese Readings of Foreign Names in Alphabetical Order, a dictionary complied by Nichigai Associates (2003), is a standard and reliable dictionary to date; it is an indispensable guide to Japanese readings of foreign names. It was compiled to meet an increasing need in this age of globalization, by strenuous examination and tenacious research of available source materials. A transcription with three stars $\left({ }^{* * *}\right)$ means that a given version is used in all the references consulted; one with two stars $\left(^{* *}\right)$ signals a version found in $80 \%$ of texts surveyed; and the one with a single star $\left(^{*}\right)$-a version present in $60 \%$ of the references consulted.

Is there any specifically "Japanese view” on James? Is it possible to name any major themes in comparative studies involving this author?

The theme of international situations (the Old vs. New Continent) in his dramatized works has a good chance with Japanese scholars and readers. In Japanese society and culture the importance of human relationships is made much of, and the virtue of "selflessness" over self-assertion practiced by his characters is (or rather used to be) appreciated by Japanese mentality. Extreme self-interest or individualism is the cause of conflict among people in Japan, whose culture is nurtured and enriched by the idea of "harmony" among people in community, expressed in such adages as「和をもつて尊しとなす」= "Reconciliation not confrontation is a virtue," "Tact(fullness) is the thing," "Civility and tacit understanding creates harmony," "Eloquence is silver, silence is gold." Are these anachronisms in our current global society? I wonder.

1 R. L. Gale, A Henry James Encyclopedia, New York: Greenwood Press, 1989. 
The Jamesian notion of "conspiracy of silence" (The Wings of a Dove), which is practiced at critical moments by his characters, in order to withhold or conceal information or knowledge from friends and enemies alike is also similar to the Japanese notion of civility. Such social custom and practice depicted and dramatized in James's stories and novels are easily appreciated by Japanese readers.

\section{How does James's complex and opaque style translate into Japanese?}

The complexity and ambiguity caused by the complex, convoluted, rhetorical style is more or less similar both in Japanese and Jamesian way of expression, in both written and spoken language. It translates well, and the transmission of nuances is made without much loss when it comes to the question of rendering the one into the other. Or perhaps similarity rather than difference may, paradoxically, create different problems.

Do Japanese translations of James's prose typically include any paratext, such as footnotes, afterwords, etc?

Yes. For example, each chapter of The Wings of the Dove has a brief synopsis of the dramatic development, which helps scholars as well as general readers better understand what is going on in the story. A similar paratext is inserted at the beginning of each section in Notes of a Son and Brother, and such paratext is provided in an earlier abridged Japanese edition of The American Scene (1976). Translators' "footnotes" are often indispensable in addition to "notes" given in the original texts.

In general, which of James's major themes do you think resonate well with the Japanese audience, and which might be of lesser interest? How do the themes of tradition, gender roles, moral and social complexities, translate into Japanese historical and social context?

Puritan heritage embedded in Jamesian way of life, the respect for "the path of duty" (義理 ·人情) may resonate with his Japanese audience, even though this again is no more true in our contemporary life. "The Path of Duty" and virtues have become an anachronism. Matthew Arnold's "Hellenism vs. Hebraism," translated into "New England conscience vs. Free Play of Imagination," might explain certain behaviors peculiar to different cultures. While to keep a certain distance in personal relationships is valued in Japanese culture, the notion of frankness and open-heartedness is an important American value, and way of life. The values and virtues peculiar to Japanese culture I mentioned above-tacit understanding without directly articulating one's emotion or thoughts-might compare with "conspiracy of silence." The "poetics of duplicity" is quite understandable to Japanese readers, which may vary in accordance with class, education, and historical changes, the variables subject to change in historical and social contexts.

Isabel Archer is "ground in the very mill of the conventional," the way of the world, Ralph says. Japanese women readers in particular will easily share Isabel's dilemma. At the same time, the defiance of Daily Miller against social customs will find quite a few admirers and supporters among Japanese readers. The great shift in the gender bias took place after the end of WWII, when things Japanese were judged as old, therefore detrimental—first at the time of Meiji Restoration in 1868, and again decisively after the end of WWII. Now, we are going through another stage of evolution. 
As a translator of James's fiction and non-fiction, what "culture bumps" have you encountered?

Translating personal pronouns is, perhaps, a major "culture bump," because in Japanese writing or speech, personal pronouns have a great variety of transcription, depending on the gender and class (social position), as well as age of the person.

Usually, in Japanese writing the subject "I" is seldom mentioned. "[I'm] going to Osaka" = "Osaka ni Ikimasu." So is "you" in conversation: "Where [Doko-he] are you going [Ikimasuka]?" = "you" is not mentioned. "[I] will [eat it later on] = [ato-de tabemasu.]" Here the subject "I" is taken for granted; but it will cause a problem, when "who or what" is the subject and holds key to understanding the situation.

Another problem is to choose a right kind of personal pronoun in Japanese, as a Japanese personal pronoun has a variety of expressions depending on gender, class, and age, which affect the relationship between the people concerned. For example, "I" can be translated in several alternatives: in the case of a male, "I" will be translated as [Boku, Ore, Washi] = 僕、俺、わし; in the case of a female, “I” will be「私、わたくし、わた し、あたし」, and “You” will be「お前、貴女、貴方、君」 depending, again, on gender, social position, and often on the age of person addressed. At the peak of feminist movement, to assert equality with boys, teenage girls employed "Boku" instead of "Atashi." They meant it in earnest, but it is too stupid an issue to take it even as a joke. Fortunately, the fad was short lived.

The question of translating personal pronouns was a great challenge while I was engaged in the translation of Dear Munificent Friends: Henry James's Letters to Four Women (ed. Susan E. Gunter, 2000). For instance, how to transcribe "Alice” (William's wife) addressed in his letters to her in Japanese?

How do you think the very complex relationship of Japanese and American cultures might colour the perception of the contrasts between his British and American characters and values, so commonly depicted in James's fiction?

Mostly likely, James must have been puzzled and annoyed by reactions shown by aloof and condescending British aristocrats. The poetics or rhetoric of "duplicity" puzzles his American characters ("A London Life," “The Liar"). By contrast, for a Japanese reader, such enigma exploited in human relationship is taken for granted, hence less of a cause for puzzlement or misapprehension.

Are any major works by James still awaiting translation into Japanese? Have there been any retranslations or particularly controversial renderings?

The American Scene (the complete edition) is now a translation in progress by the same three translators of his Autobiography: A Small Boy and Others (1994), Notes of a Son and Brother, "The Middle Years" (2009). Most recent achievements in this category are the translations of Dear Munificent Friends: Henry James's Letter to Four Women (2014) and The Journal of Alice James (2016).

The Golden Bowl, The Turn of the Screw, The Aspern Papers, The Portrait of a Lady have at least two different versions that I know of. 


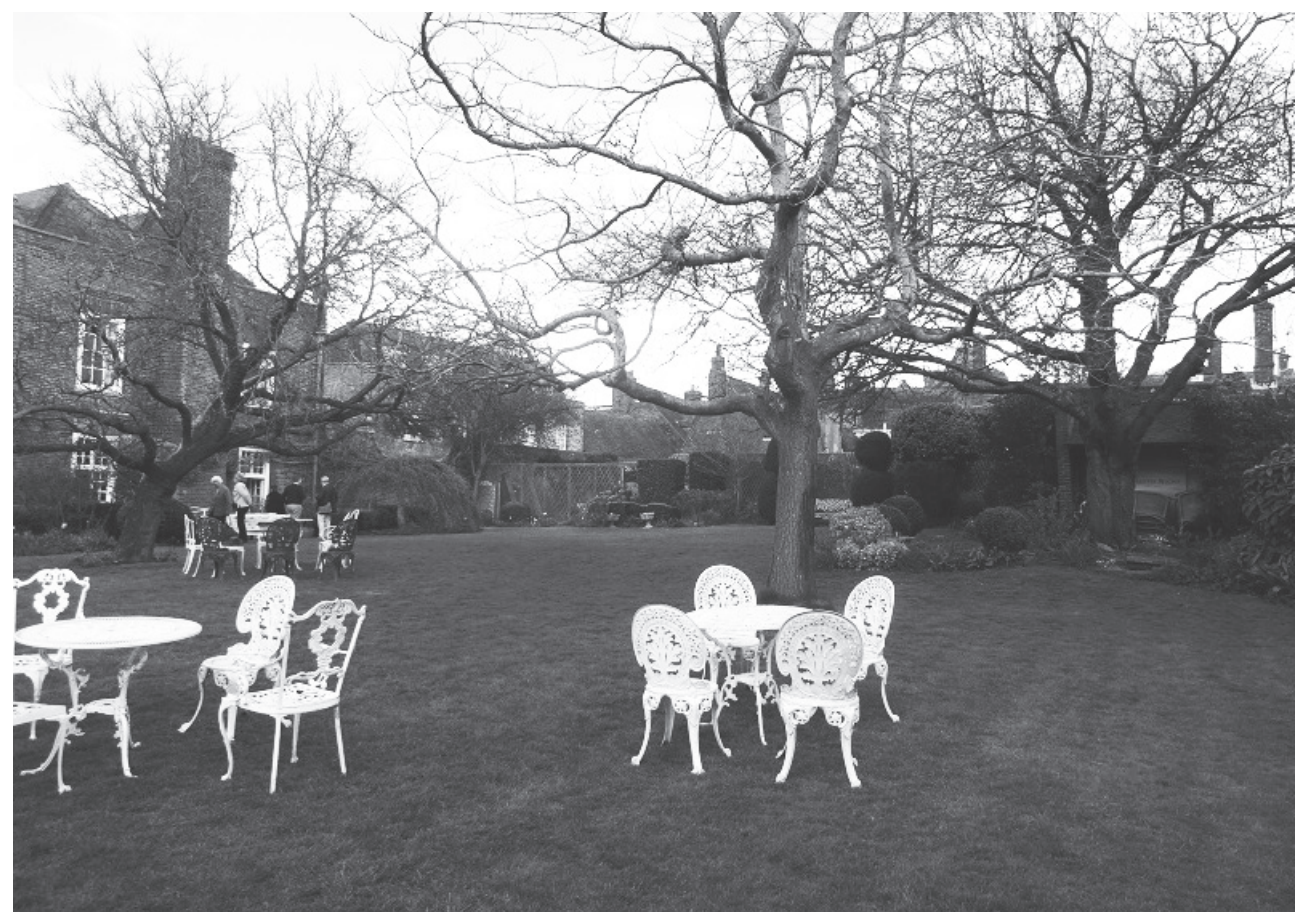

Lamb House. Photo by Sonoko Saito

The vicissitudes in social and cultural changes, and subtle changes in language itself, will demand new translations of works of art, regardless of authors. The prime example is the rendition of Shakespeare, which was first made by Shoyo Tsubouchi with his translation of Julius Caesar in 1884, and in 1928, followed by the complete works of Shakespeare in forty volumes in 1933; retranslation into "modern Japanese" is now going on. Furthermore, since Tsubouchi's there have been at least three major variations; the most popular and latest accomplishment is Yushi Odashima's The Complete Works of Shakespeare (1973-1980).

Over twenty years ago, in your contribution to Huck Gutman's As Others Read Us (1991) you said that some $80 \%$ of literary translation into Japanese were of American authors, and that Henry James was one of the most influential and discussed writers, along with William Faulkner, Nathaniel Hawthorne, Herman Melville and Emily Dickinson. Is this still the case?

My chapter in Gutman's book, "Cultural Colonization? American Literary Studies in Japan" in As Others Read Us (1991), was based on my presentation at the Bellagio Conference in 1987. In view of the way we live in the twenty-first century, twenty years is a long timelong enough to change the cartography of literary studies, or a cognitive map of academic approaches to and reception of literatures other than one's own.

Just the same, the percentage of literary translation of American writers in general still holds true; yet social/political vicissitudes have brought about a radical change in the reception of American writers in the past twenty some years. The emergence and recognition of writers of minority groups, namely Hispanic- and Asian-American writers, is a decisive factor 
in changing the literary cartography. The hyphenated modifiers such as Jewish-, Native-, or African-American are seldom used now, in the case of Jewish-American writers in particular.

Accordingly, translations of "newly canonized" writers of old and new have increased; and in addition to professional translators, scholars of American/English literatures, and poets and novelists as well, produce a great number of translations themselves. The aim may well be to meet the needs of students in Humanities, and readers in general.

Translation is no mere transaction of languages, but a transmission of cultural and social changes. A great number of Japanese words (signifiers) are now dead language without the "signified." Language itself changes; and new invented objects require new terminology. To give one example, since Tsubouchi Shoyo' ${ }^{2}$ translation of The Works of Shakespeare in $1884(1928,1933)$, there have been quite a few Japanese versions of the playwright/poet; Yushi Odashiima's ${ }^{3}$ Shakespeare is the latest translation done in good colloquial Japanese, popular, and in paperback.

As for American authors, the works of Paul Auster, Raymond Carver, Grace Paley, Toni Morrison, Alice Walker, and the Canadian Alice Munro in translation crowd the shelves of nation-wide bookstores, and on the Amazon website. It may seem curious to overseas readers, however, that many of J.C. Oates's long heavy novels have been translated, as she has been seen for years as a possible Nobel Prize winner.

Besides definitive translations of Nathaniel Hawthorne, Herman Melville, Edgar Allan Poe, Emily Dickinson, Mark Twain, and Henry James, updated translation of Fransic Scott Fitzgerald's The Great Gatsby by Haruki Murakami ${ }^{4}$ has triggered new academic interest in Fitzgerald; this is also true of D.J. Salinger, and Vladimir Nabokov. Certainly, James is no exception; The Selected Works of Henry James in eight volumes ${ }^{5}$ published in 1983 is an authentic and noteworthy achievement; there are a great many translations of his individual short stories, and novellas. Also recent years have seen the translations of his non-fictionAutobiography: A Small Boy and Others (1994); Notes of a Son and Brother (2009); and a collection of his letters-Dear Munificent Friends (2014).

\section{What is James's status in academia, and how does the literary canon of academics compare to that of the readers?}

The status of Henry James in academia is solid, but less popular than that of Twain, Faulkner, or Hawthorne; this indicates that he is less frequently selected as the object of doctoral dis-

2 Shoyo Tsubouchi (1859-1935), a noted novelist, playwright, critic of the Meiji period; his translation of Julius Caesar in 1884 was the first Shakespeare translation in Japan. Coincidentally, Tsubouchi wrote The Essence of the Novel: in Praise of Realism (1885), which might correspond to Henry James's "The Art of Fiction" (1884). [All the following footnotes in this interview supplied by Professor Beppu.]

3 Takeshi Odashima (born 1930), Professor Emeritus of Tokyo University, a translator of plays, and a theater critic.

4 Haruki Murakami (born 1949), a popular novelist, who is on the list of the Nobel Prize candidates. He seems to be under a great influence of American literature, or American culture.

5 The Selected Works of Henry James supervised by Yoshimi Kudo, and compiled by Akio Namekata, published by Kokusho-Kankoh-kai. Vol. 1: The Portrait of a Lady; Vol. 2: The Spoils of Poynton, What Maisie Knew, In the Cage; Vol. 3: The Wings of the Dove; Vol. 4: The Ambassadors; Vol. 5: The Golden Bowl; Vol. 6: The Ivory Tower, The Sense of the Past; Vol. 7: Short Stories (A Passionate Pilgrim, The Beast in the Jungle, "The Bench of Desolation," "The Jolly Corner," The Great Good Place, etc.); Vol. 8: Essays and Letters (Walt Whitman, Hawthorne, Emerson, "The Art of Fiction," etc.). 
sertations. Certainly, James still is read and studied in graduate schools; but he is seldom chosen as the subject/theme of doctoral dissertations in recent years. Furthermore, classic nineteenth-century American writers are less avidly read by general readers who are keen on contemporary American writers-Paul Auster, Toni Morrison, Alice Walker, or winners of Pulitzer Prize, or other prestigious awards.

In As Others Read Us, you also claim that American literary studies in Japan are focused on producing analyses and textbooks for domestic market. Does this apply to James? How and to what extent is his fiction present in academic curricula?

Yes, this has been the case in the English curricula in Japan. Annotated (sometime heavily annotated) short stories used to be published as texts for undergraduate students in the Humanities Departments. However, recent governmental policies initiated by the Ministry of Education and Science in the twenty-first century and aimed at reforming the liberal arts education at colleges and universities, focus on interdisciplinary and practical curricula. This new "reformed" policy is in fact a menace to literary studies in higher education. The emphasis on so-called "communicative/practical" English has brought about a serious decrease in the literary courses taught in English Departments. English/American literary courses have given way to "practical" English courses, and recommended texts are naturally non-literary, journalistic reading texts other than poetry or short fiction.

\section{Are there any academic or literary societies focused on James in Japan?}

There are many literary societies on individual American writers. Thoreau Society is the oldest of the kind, but there are also others focused on Hawthorne, Poe, Melville, Dickinson, Twain, Faulkner, Hemingway, Bellow, and African-American writers, etc., with long-established history, except Melville Society, which is comparatively new. A few of them have excellent journals. But so far there is no academic Henry James Society here, for reasons hard to give, even though James scholarship is solid and stable, and he enjoys a substantial popularity among academics. To ameliorate this imbalance, now about five years ago, a group of James scholars (myself being one) organized a study group and since then we have held a meeting of James studies each year, with full programs: one paper presentation (or a lecture), a close reading of a selected text, and a symposium. The meeting is held once a year alternately in Tokyo (East) and Kyoto or Kobe (West). We also have a film showing, starting with "The Jolly Corner," What Maisie Knew, "The Altar of the Dead," and at the sixth meeting (Septemeber 3-4, 2016) The Bostonians, followed by a discussion. So far there are 25 to 30 members who regularly attend the meeting. The highlight of this latest meeting was the publication of Reading Henry James, Now: New Essays Commemorating the Centennial of His Death. The collection of essays is a handsome volume with twenty contributions (in Japanese). I am hoping that a generation of young James scholars will follow us. And as a form of commemoration of the Centennial of Henry James's death, we have just published Reading Henry James, Now: New Essays Commemorating the Centennial of His Death (2016). ${ }^{6}$

${ }^{6}$ Reading Henry James, Now: New Essays Commemorating the Centennial of His Death (2016), with contributions by: Shigemi Satomi, Yoshio Nakamura, Hitomi Nabae, Taeko Kitahara, Seichi Nakai, Tatsuya Namoto, Yuko Nakagawa, Naoyuki Mizuno, Sonoko Saito, Kazuma Matsui, Satomi Hatae, Noriko Sunagawa, Noriko Ishizuka, Midori Machida, Emi Matsuura, Chikako Tustsumi, Shizue Ebine, Takako Fukuda, and Keiko Beppu. 


\section{What are your other academic interests? Do they connect to James?}

I am interested in women poets: I have written articles on Emily Dickinson, Sylvia Plath, Anne Sexton, and Marianne Moore in particular, who was an enthusiast of James. I have written a few essays on Moore which appeared in academic journals. Edna St. Vincent Millay is another poet whom I love. She wrote sonnets when modernism was in vogue and having its high time. I am interested in her choice of lyric form of sonnets to express her story and her desire. As for novelists-Joyce Caral Oates, Joan Didion, Cynthia Ozick (another James fan). Recently I've read a paper at the James Conference in Rome, discussing Ozick's "Dictation," and The Foreign Bodies.

\section{Professor Beppu, thank you very much for the interview!}

Interview by Dorota Guttfeld*

* Ph.D., is an Assistant Professor in the Department of English at Nicolaus Copernicus University in Toruń, Poland. Her academic interests include literary and audiovisual translation, as well as Anglophone speculative fiction. As a member of Translation Studies Unit she teaches translation and stylistics for translators. E-mail: gutt@umk.pl. 